\title{
First tristatic studies of meso-scale ion-neutral dynamics and energetics in the high-latitude upper atmosphere using collocated FPIs and EISCAT radar
}

\author{
A. L. Aruliah, E. M. Griffin, I. McWhirter, A. D. Aylward, E. A. K. Ford, \\ and A. Charalambous \\ Atmospheric Physics Laboratory, University College London, London, UK
}

\author{
M. J. Kosch \\ University of Lancaster, UK
}

C. J. Davis and V. S. C. Howells

Rutherford Appleton Laboratory, Chilton, Didcot, Oxfordshire, UK

Received 21 August 2003; revised 19 November 2003; accepted 3 December 2003; published 3 February 2004.

[1] A unique experiment was undertaken during the nights of 27 and 28 February 2003. Tristatic Fabry-Perot Interferometer (FPI) measurements of the upper thermosphere were co-located with tristatic EISCAT radar measurements of the ionosphere. Tristatic measurements should remove assumptions of uniform wind fields and ion drifts, and zero vertical winds. The FPIs are located close to the 3 radars of the EISCAT configuration in northern Scandinavia. Initial studies indicate that the thermosphere is more dynamic and responsive to ionospheric forcing than expected. Mesoscale variations are observed on the scales of tens of kilometers and minutes. The magnitude of the upper thermosphere neutral wind dynamo field is on average $50 \%$ of the magnetospheric electric field and contributes an average magnitude of $41 \%$ of in-situ Joule heating. The relative orientations of the 2 dynamo field vectors produce a standard deviation of $\pm 65 \%$ in the contribution of the neutral wind dynamo. INDEX TERMS: 0310 Atmospheric Composition and Structure: Airglow and aurora; 0358 Atmospheric Composition and Structure: Thermosphere-energy deposition; 2407 Ionosphere: Auroral ionosphere (2704); 2411 Ionosphere: Electric fields (2712); 2427 Ionosphere: Ionosphere/atmosphere interactions (0335). Citation: Aruliah, A. L., E. M. Griffin, I. McWhirter, A. D. Aylward, E. A. K. Ford, A. Charalambous, M. J. Kosch, C. J. Davis, and V. S. C. Howells (2004), First tristatic studies of meso-scale ion-neutral dynamics and energetics in the high-latitude upper atmosphere using collocated FPIs and EISCAT radar, Geophys. Res. Lett., 31, L03802, doi:10.1029/ 2003 GL018469.

\section{Introduction}

[2] The EISCAT radar is notable for being the only radar system producing true tristatic ionospheric measurements. Other radar systems with only one or two beams rely on beam-swinging techniques to determine orthogonal components. This assumes an unchanging plasma velocity during a scan. Discussion of the assumptions required by beamswinging is presented by Etemadi et al. [1989].
[3] There are still outstanding questions in ion-neutral dynamics that can only be resolved by common volume tristatic measurements of the meso-scale behavior of the ionosphere and thermosphere. The role of the thermosphere is undervalued owing to assumptions of large spatial and temporal scale sizes. It is recognized that there is a significant element missing from the energy budget that is likely to be attributable to mesoscale phenomena such as gravity waves [Innis et al., 1998] and plasma velocity variability [Codrescu et al., 2000]. Yet there are few measurements. Co-located ion-neutral observations were first made by the Dynamics Explorer satellites [e.g., Killeen et al., 1984]. Only a few groups have performed experiments using both FPIs and radar to investigate large-scale ion-neutral energetics and dynamics over a scale size of hundreds of kilometers [e.g., Cierpka et al., 2000; Aruliah and Griffin, 2001]. There are also only a few published investigations of mesoscale spatial variations using two FPIs in close proximity [e.g., Greet et al., 1999; Ishii et al., 2001]. In general the radar community derives neutral parameters from ionospheric measurements by way of models of the thermosphere. Such models have great value for determining climatologies, but should be treated with care for modeling specific behavior [e.g., Griffin et al., 2003].

\section{The Case for Tristatic Observations}

[4] Tristatic measurements of thermospheric winds allow true determination of the velocity vector. The thermospheric wind velocity vector $\mathbf{U}$ appears in several fundamental equations such as the calculation of current $\mathbf{j}=N_{e} q(\mathbf{V}-\mathbf{U})$ where $N_{e}$ is the electron density, $q$ is the electron charge, $\mathbf{V}$ is the plasma velocity; or the effective electric field $\mathbf{E}^{\prime}=\mathbf{V} \times$ $\mathbf{B}+\mathbf{U} \times \mathbf{B}$, which includes a term for the neutral wind dynamo, $\mathbf{U} \times \mathbf{B}$, as well as the magnetospheric electric field $\mathbf{E}(=\mathbf{V} \times \mathbf{B})$. Both these equations may be used to calculate Joule heating, which is the second largest sink for dissipation of magnetospheric energy [e.g., Thayer et al., 1995]. However, the majority of existing studies ignore or grossly simplify the influence of the thermosphere because at high latitudes the neutral wind dynamo is assumed to be an 
order of magnitude smaller than the magnetospheric dynamo [e.g., Mozer, 1973].

[5] Further thermospheric influence comes from the neutral temperature and vertical wind component which can modify the chemical composition. Changes in temperature affect rates of chemical reactions; while up-welling or down-welling alters the ratio of molecular to atomic particles, which consequently affects the production and loss mechanisms for plasma densities. Killeen et al. [1984] have shown that the large-scale nighttime response time can be between 1-3 hours. This experiment shows a more rapid response on the meso-scale than previously assumed. Thus compositional changes in the thermosphere due to rapid upor down-welling are currently not well modeled during geomagnetically active conditions owing to underestimation of the response time.

\section{The Instruments}

[6] The Atmospheric Physics Laboratory (APL) at University College London operates a FPI at the Kiruna Esrange Optical Platform System (KEOPS) in Sweden $\left(67.8^{\circ} \mathrm{N}, 20.4^{\circ} \mathrm{E}\right)$ and in November 2002 installed another at the Sodankylä Geophysical Observatory in Finland $\left(67.4^{\circ} \mathrm{N}, 26.6^{\circ} \mathrm{E}\right)$. The first tristatic observations of thermospheric winds were achieved through collaboration with the University of Lancaster, which has a FPI at Skibotn in Norway $\left(69.3^{\circ} \mathrm{N}, 20.4^{\circ} \mathrm{E}\right)$. The three FPIs are located close to the three EISCAT radar receivers.

[7] The FPI observes the red line aurora and airglow emission at $630 \mathrm{~nm}$ wavelength. Measurement of the Doppler shift and Doppler broadening of the emission line allows calculation of thermospheric wind speeds and temperatures at an altitude of around $240 \mathrm{~km}$. The FPI line-ofsight measurement has a $1^{\circ}$ field-of-view which is directed by a pointing mirror using a fixed elevation angle. All the FPIs view the common volume tristatic position called position $\mathrm{A}\left(69.3^{\circ} \mathrm{N}, 25.0^{\circ} \mathrm{E}\right)$ and 4 cardinal positions (north, east, south, west), as well as the vertical and a calibration lamp. The elevation angles are $45^{\circ}$ for the KEOPS and Sodankylä FPIs, and $51.5^{\circ}$ for the Skibotn FPI. Combining all these line-of-sight observations provides a grid of observations and thus a useful wider spatial context to the thermospheric wind, intensity and temperature fields.

[8] The FPIs collect data continually throughout the period September-April. The only requirement is that observations are made during the night owing to the low intensities of the airglow and auroral emissions, and during clear skies because light scattered by cloud loses directional information.

[9] Meanwhile the EISCAT radar at Tromsø and the receivers at Sodankylä and Kiruna were aimed in the direction of Position A and a fixed beam CP1-like mode was used to make simultaneous tristatic observations of a common volume with the FPIs. The radar-FPI campaign covered 24 hours over two consecutive nights: 1630-0430 UT for the nights of 27-28 February 2003 and 28 February01 March 2003. This paper concentrates on the first night.

\section{Results}

[10] The upper atmosphere at high-latitudes can be very dynamic. This makes it difficult to ensure that the FPIs and
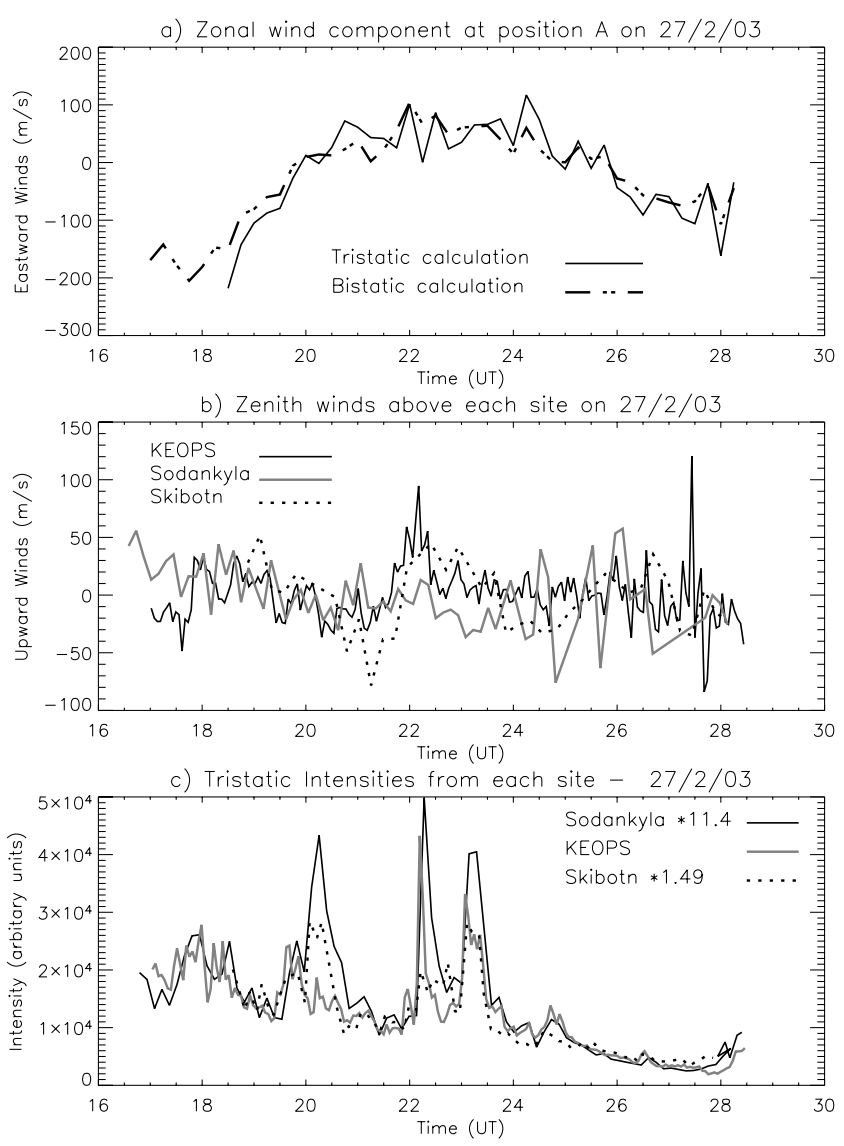

Figure 1. (a) Zonal winds on 27 February 2003 calculated using line-of-sight measurements interpolated to 15 minute intervals from all 3 FPIs which is compared with a calculation using only 2 FPIs with the assumption of a zero vertical wind component. (b) Comparison of the actual vertical wind components above each of the 3 FPI sites showing considerable though consistent meso-scale structure. Note the different time resolutions: KEOPS has 3.5 minutes, Sodankyla has 8.7 minutes and Skibotn has 13.9 minutes. (c) Comparison of the intensities from the 3 FPIs, where the Sodankyla and Skibotn intensities are multiplied by 11.4 and 1.49 , respectively, to scale with KEOPS.

radars are viewing the same volume. The footprint of the radar at the tristatic A position is about $3 \mathrm{~km}$ wide and its position is known precisely. The Tromsø radar is the active radar, which means that measurements are taken at all altitudes along its line-of-sight. This allows measurement of the height of the $\mathrm{F}_{2}$ electron density peak, $\mathrm{h}_{\mathrm{m}} \mathrm{F}_{2}$. The peak emission height for the $630 \mathrm{~nm}$ emission is approximately 1 scale height below $h_{m} F_{2}$, which in this altitude region is approximately $50 \mathrm{~km}$. The tristatic A position was chosen assuming that the quiet steady state $630 \mathrm{~nm}$ emission peak height is $240 \mathrm{~km}$. In reality the two nights were geomagnetically active $\left(\mathrm{K}_{\mathrm{p}} \sim 4\right)$. EISCAT measurements show that $\mathrm{h}_{\mathrm{m}} \mathrm{F}_{2}$ varies between $280 \mathrm{~km}$ and $400 \mathrm{~km}$, with a considerable variability of around $\pm 50 \mathrm{~km}$. As a result the $630 \mathrm{~nm}$ emission height is probably not $240 \mathrm{~km}$ for large periods of the night. However, there is a close correspondence between the intensity variations of the three FPIs for the majority of the time as shown in Figure 1c. This implies that the deviation from $240 \mathrm{~km}$ is not large, which is consistent 
with the fact that the $630 \mathrm{~nm}$ emission peak is very broad, with a full width half maximum value of up to $100 \mathrm{~km}$ [e.g., Solomon et al., 1988]. By calculating the gradient in the wind speeds across the field-of-view of the FPIs, it is possible to estimate that if the emission height increases by $50 \mathrm{~km}$ (thus increasing the radial extent of the line-ofsight measurement) the change in magnitude is about $11 \mathrm{~ms}^{-1}$. In comparison, the average error on the individual wind measurements is about $\pm 15 \mathrm{~ms}^{-1}$ for all the FPIs, since the integration times are chosen to compensate for the sensitivity of the detectors while maximizing time resolution. As can be seen from Figures $1 \mathrm{~b}$ and 1c, Skibotn has the lowest time resolution which smoothes out large, rapid variations.

[11] Figure 1a compares the calculation of the zonal component of the wind vector measured at position A using all three FPIs, with a calculation using only the two FPIs at KEOPS and Sodankylä. The bistatic calculation requires the assumption that the vertical component is zero. This is a commonly used assumption since the vertical component is usually an order of magnitude smaller than the horizontal component. The average difference between the tristatic and bistatic calculations of the zonal winds is $25 \mathrm{~ms}^{-1}$ with a standard deviation of $\pm 18 \mathrm{~ms}^{-1}$. The difference is consistent with the observation that the individual FPI measurements of vertical winds above each site are not zero, but generally vary between $\pm 40 \mathrm{~ms}^{-1}$ (Figure 1b), and thus contribute to the line-of-sight measurement.

[12] The three independent sets of vertical wind measurements shown in Figure $1 \mathrm{~b}$ also reveal how spatially variable the winds are on the meso-scale, since the observations are separated by only $200-300 \mathrm{~km}$. KEOPS and Skibotn are on a similar longitude and KEOPS and Sodankyla are on a similar latitude. Similar clear structures appear at the different sites, sometimes separated by a time lag, e.g., there is a large downwelling followed by an upwelling between 21-23 UT seen at KEOPS and Skibotn, with a 15 minute time delay between the sites. KEOPS shows a vertical wind component rising to $95 \mathrm{~ms}^{-1}$ upwards at $2210 \mathrm{UT}$ that then drops in magnitude during the period 2200-2230 UT. Skibotn, which lies on a similar meridian, shows a similarly large and rapid upwelling that is sustained between 22-23 UT. It is unlikely that these large changes in wind speeds are due to altitude changes of the $630 \mathrm{~nm}$ emission height since $\mathrm{h}_{\mathrm{m}} \mathrm{F}_{2}$ shows only a steady decline in altitude from $380 \mathrm{~km}$ to $315 \mathrm{~km}$ between $21-23 \mathrm{UT}$.

[13] The source of the upwelling can be seen in Figure 2 which shows the component of the EISCAT plasma velocities in the northward direction perpendicular to the magnetic field. These velocities are highly variable, with a standard deviation of over $\pm 500 \mathrm{~ms}^{-1}$. There is a sudden spike when the velocity jumps from $+262 \mathrm{~ms}^{-1}$ at 2155 UT to $-4909 \mathrm{~ms}^{-1}$ at $2156 \mathrm{UT}$ and then drops rapidly back towards zero. Several intermediate data points confirm this as a real observation rather than noise. The all-sky camera image from Sodankylä at 21:59:20 UT shows an auroral feature in the near vicinity which is the likely source of localized high electric fields causing this velocity spike.

[14] Overlaid on this plot is the line-of-sight observation of tristatic A from KEOPS. This is the FPI with the highest time resolution (integration time is 20 seconds). The wind speeds have been multiplied by 30 to show them on the

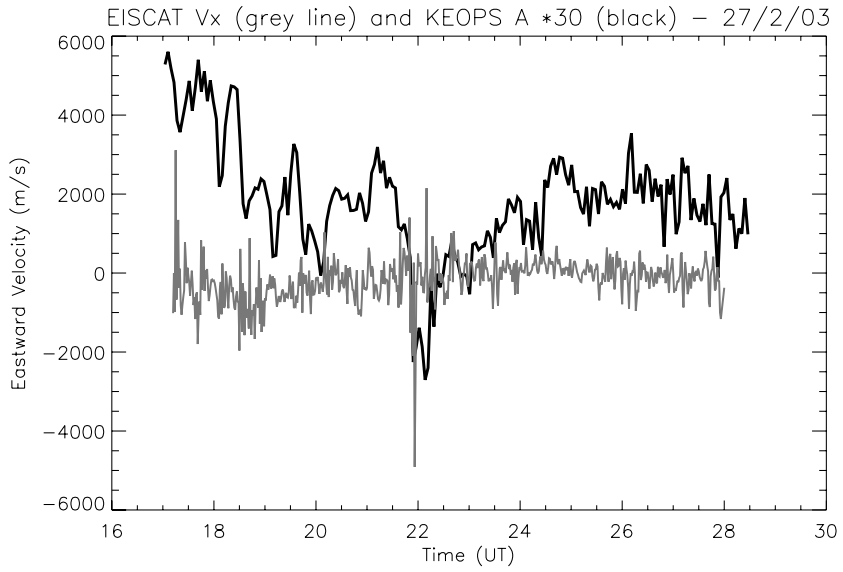

Figure 2. Plasma velocities from the EISCAT radar on 27 February 2003 at position A (grey line). Superposed are the line-of-sight neutral winds from the KEOPS FPI multiplied by 30 to appear on the same scale (black line). There is a sharp increase and decrease in the plasma velocities at around 2200UT and also a rapid peaking of the line-of-sight wind in the direction from KEOPS to position A.

same scale. There is a large and clear increase in the line-ofsight neutral wind component that corresponds quite closely to the increase in plasma velocity around 22 UT. Between 2151-2154 UT the KEOPS line-of-sight winds show an acceleration of $25 \mathrm{~ms}^{-2}$. This compares with an average acceleration of $-121 \mathrm{~ms}^{-2}$ for the plasma velocities between 2148-2156 UT. The importance of this figure is the rapid speed of the thermospheric response on the meso-scale. At these accelerations it would take around 72 seconds for the neutral wind to accelerate from zero to $1 / \mathrm{e}$ times the maximum plasma velocity. Consequently this acceleration is predominantly due to the vertical wind component, as shown in Figure 1b, rather than horizontal ion drag, since the e-folding response time for ion-drag calculated from the EISCAT electron density measurement is over 1 hour, using the definition from Killeen et al. [1984], for example. There is also a large amount of in-situ Joule heating between 2130-2230 UT which will cause up-welling.

[15] The FPIs also measure thermospheric temperatures. Comparison with the EISCAT ion temperatures has proved interesting and points to problems in the assumptions used in the standard analysis routine. These temperature observations will be discussed in a companion paper by Griffin et al. [in preparation, 2004].

[16] Theoretical models, such as the Coupled Thermosphere Ionosphere Plasmasphere model (CTIP), have severely underestimated thermospheric temperatures. Codrescu et al. [2000] attribute this to ignoring the variability of the ionospheric velocities and therefore underestimating Joule heating. Our own studies have shown significant mesoscale variability in the thermosphere as well [Aruliah and Griffin, 2001]. One aim of this collocated tristatic experiment is to investigate how much thermospheric variability adds to the effects of ionospheric variability on Joule heating. Joule heating peaks at around $150 \mathrm{~km}$ altitude and most studies deal with the height-integrated Joule heating. This experiment measures only the nighttime F-region. However, at 
nighttime it is expected that the currents and Joule heating in the F-region become very significant in importance because the E-region becomes relatively weak. This is because there is no photoionization and, since recombination is rapid at E-region heights owing to the greater particle density, the ions and electrons are removed, and are only replenished by particle precipitation. However, nighttime particle precipitation is more intense than at daytime, resulting in sporadic enhancement of the E-region which complicates the interpretation of the data; producing questions about where the main source of heating is etc. These will be considered in a further study.

[17] The calculation of the in-situ Joule heating for the night of 27 February 2003 has been done both with and without the neutral wind dynamo. This assumes that Joule heating is proportional to $\mathrm{N}_{\mathrm{e}}{ }^{*} \mathbf{E}_{\text {perp }}^{\prime 2}$, where $\mathbf{E}_{\text {perp }}^{\prime}$ is the component of the effective electric field perpendicular to B. The average of the magnitudes of the percentage differences for the whole night, $\left|\left(\mathbf{E}_{\text {perp }}^{\prime 2}-\mathbf{E}_{\text {perp }}^{2}\right)\right| / \mathbf{E}_{\text {perp }}^{\prime 2}$, is $41 \%$ of the total in-situ Joule heating. This is consistent with a model simulation by Thayer et al. [1995] that has shown that ignoring the flywheel effect can introduce a $40 \%$ error in the calculation of height-integrated polar cap Joule heating during steady state moderately active conditions. Cierpka et al. [2000] made simultaneous FPI and EISCAT measurements of neutral and plasma velocities and temperatures to study the effect of neglecting the neutral atmosphere and found errors of at least $60 \%$ in calculating Joule heating in the F-layer.

[18] The magnitude of the neutral wind dynamo electric field in the upper thermosphere is on average $50 \%$ of the magnetospheric dynamo, which is consistent with Killeen et al. [1984]. The relative orientation of the fields is also vital. The neutral wind dynamo electric field varies fairly smoothly while the magnetospheric electric field is highly variable. The vector sum of the two fields results in a standard deviation of $\pm 65 \%$ for the difference in the Joule heating term due to the neutral wind dynamo. There is also a definite trend with respect to geomagnetic activity, so that the largest differences occur during the quiet post-storm conditions. This is due to the inertia of the thermosphere, which maintains the high storm time winds [Aruliah et al., 1999] while the plasma velocities respond immediately to the reduction in the magnetospheric electric field.

\section{Conclusion}

[19] Tristatic FPI measurements allow a very detailed study of the meso-scale structure of the upper thermosphere that complement radar studies of the ionosphere. The initial results presented here show a spatially variable thermosphere at high latitudes, which is also capable of rapid response to ion forcing over meso-scale distances. The contribution of the neutral wind dynamo to Joule heating appears to be highly variable and can increase and decrease the effective electric field considerably since it is on average $50 \%$ of the magnitude of the magnetospheric electric field.
On the first night of this experiment the contribution of the upper thermosphere neutral wind dynamo to in-situ Joule heating is $41 \%( \pm 65 \%)$.

[20] Acknowledgments. The APL team would like to acknowledge funding from the Lapbiat grant, administered by the Sodankylä Geophysical Observatory, together with their generous help in logistics. Also acknowledging PPARC grant PPA/G/O/2001/00484. EISCAT is an International Association supported by Finland (SA), France (CNRS), the Federal Republic of Germany (MPG), Japan (NIPR), Norway (NFR), Sweden (NFR) and the United Kingdom (PPARC). We thank the institutes who maintain the IMAGE magnetometer array and ESRANGE KEOPS facility. Finally, we would like to dedicate this paper to the memory of Professor Phil Williams who has been a leading light in the inception of EISCAT and the exploitation of this important facility.

\section{References}

Aruliah, A. L., I. C. F. Müller-Wodarg, and J. Schoendorf (1999), The consequences of geomagnetic history on the high-latitude thermosphere and ionosphere: Averages, J. Geophys. Res., 104(A12), 28,073-28,088.

Aruliah, A. L., and E. Griffin (2001), Meso-scale structure in the highlatitude thermosphere, Annales Geophys., 19, 37-46.

Cierpka, K., M. J. Kosch, M. Rietveld, K. Schlegel, and T. Hagfors (2000), Ion-neutral coupling in the high-latitude F-layer from incoherent scatter and Fabry-Perot interferometer measurements, Annales Geophys., 18, $1145-1153$.

Codrescu, M. V., T. J. Fuller-Rowell, J. C. Foster, J. M. Holt, and S. J. Cariglia (2000), Electric Field variability associated with the Millstone Hill electric field model, J. Geophys. Res., 105(A3), 5265-5273.

Etemadi, A., S. W. H. Cowley, and M. Lockwood (1989), The Effect of Rapid Changes in Ionospheric Flow on Velocity Vectors Deduced From Radar Beam-Swinging Experiments, J. Atmos. Terr. Phys., 51, 125-138.

Greet, P. A., M. G. Conde, P. L. Dyson, J. L. Innis, A. M. Breed, and D. J. Murphy (1999), Thermospheric wind field over Mawson and Davis, Antarctica: simultaneous observations by two Fabry-Perot spectrometers of $630 \mathrm{~nm}$ emission, J. Atmos. Terr. Phys, 61, 1025-1045.

Griffin, E. M., A. L. Aruliah, I. C. F. Müller-Wodarg, and A. D. Aylward (2003), Comparison of High-Latitude Thermospheric Meridional Winds I: Optical and Radar Experimental Comparisons, Ann. Geophys, in press. Griffin, E. M., A. L. Aruliah, I. McWhirter, A. D. Aylward, E. A. K. Ford, A. Charalambous, M. J. Kosch, C. J. Davis, and V. S. C. Howells (2004), Investigation of simultaneous, co-located ion and neutral temperatures from the tristatic FPI-EISCAT radar experiment, Geophys. Res. Lett, in preparation.

Innis, J. L., P. A. Greet, and P. L. Dyson (1998), Are polar cap gravity waves a heat source for the high-latitude thermosphere?, Geophys. Res. Lett., 25, 1487-1490

Ishii, M., M. Conde, R. W. Smith, M. Krynicki, E. Sagawa, and S. Watari (2001), Vertical wind observations with two Fabry-Perot interferometers at Poker Flat Alaska, J. Geophys. Res, 106(A6), 10,537-10,551.

Killeen, T. L., P. B. Hays, G. R. Carignan, R. A. Heelis, W. B. Hanson, N. W. Spencer, and L. H. Brace (1984), Ion-Neutral Coupling in the High Latitude F-Region: Evaluation of Ion Heating Terms from Dynamics Explorer 2, J. Geophys. Res, 89, 7495-7508.

Mozer, F. S. (1973), Analysis of Techniques for Measuring DC and AC Electric Fields in the Magnetosphere, Space Sci. Rev, 14, 272.

Solomon, S. C., P. B. Hays, and V. J. Abreu (1988), The auroral 6300A emission: Observations and modeling, J. Geophys. Res., 93(A9), 98679882.

Thayer, J. P., J. F. Vickrey, R. A. Heelis, and J. B. Gary (1995), Interpretation and modelling of the high-latitude electromagnetic energy flux, J. Geophys. Res., 100(A10), 19,715-19,728.

A. L. Aruliah, A. D. Aylward, A. Charalambous, E. A. K. Ford, E. M. Griffin, and I. McWhirter, Atmospheric Physics Laboratory, University College London, 67-73, Riding House Street, London, UK. (a.aruliah@ ucl.ac.uk)

M. J. Kosch, University of Lancaster, UK.

C. J. Davis and V. S. C. Howells, Rutherford Appleton Laboratory, Chilton, Didcot, Oxfordshire, UK. 